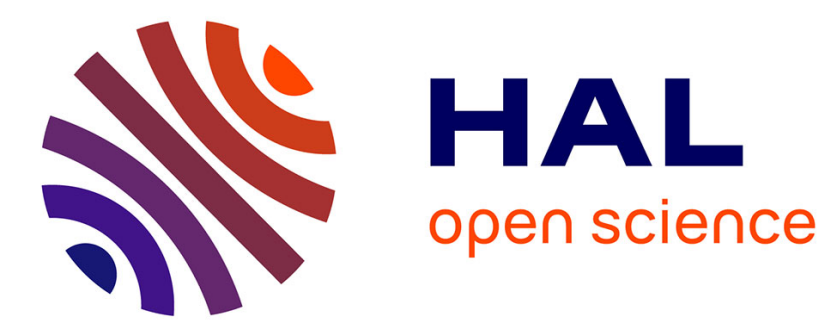

\title{
Perception of old musical instruments
}

Stéphane Vaiedelich, Claudia Fritz

\section{To cite this version:}

Stéphane Vaiedelich, Claudia Fritz. Perception of old musical instruments. Journal of Cultural Heritage, 2017, 27 (Supplement), pp.S2-S7. 10.1016/j.culher.2017.02.014 . hal-01521107

\section{HAL Id: hal-01521107 https: / hal.sorbonne-universite.fr/hal-01521107}

Submitted on 11 May 2017

HAL is a multi-disciplinary open access archive for the deposit and dissemination of scientific research documents, whether they are published or not. The documents may come from teaching and research institutions in France or abroad, or from public or private research centers.
L'archive ouverte pluridisciplinaire HAL, est destinée au dépôt et à la diffusion de documents scientifiques de niveau recherche, publiés ou non, émanant des établissements d'enseignement et de recherche français ou étrangers, des laboratoires publics ou privés. 


\title{
Perception of old musical instruments
}

\author{
Stéphane Vaiedelich ${ }^{1}$ and Claudia Fritz ${ }^{2}$ \\ ${ }^{1}$ Cité de la musique - Philharmonie, Équipe Conservation Recherche - Musée de la \\ musique, F-75019 Paris, France \\ ${ }^{2}$ Sorbonne Universités, UPMC Univ Paris 06, CNRS, UMR 7190, Institut Jean Le \\ Rond d'Alembert, F-75005 Paris, France
}

\begin{abstract}
Defining what is an old instruments is complex. In a general way, we can distinguish two categories of old instruments. On one hand, there are the instruments which are not or barely in use nowadays. Due to a period of abandonment, those instruments are representative of an epoch different from ours and can be relatively easily dated. On the other hand, there are the instruments which are still being played despite having been made a few centuries ago. Time and use have usually given them a patina, so they are perceived as old in terms of visual aspect, but they have usually been modified as well and so they can be perceived as contemporary in terms of sound.

Do we understand an old instrument by hearing it? Do we actually even need to hear it to understand it? This article is meant to provide some thoughts on these questions, to highlight the links between sight and hearing in our perception of a musical instrument and to illustrate how documentation and scientific knowledge can influence this perception ${ }^{1}$.
\end{abstract}

\section{Introduction}

For most thinkers - from a Western society at least - the musical instrument seems to have to be defined, a priori, through its sound production function. In this way, it is defined as a device/an artificial machine/a human material product, allowing the supply of "sound objects", considered to be musical by the culture within which the instrument is used [1]. Thus, whether the instrument is in a playing state or not and is submitted to scientific scrutiny as a whole or a fraction, the study and documentation of this musical instrument cannot leave out the analysis of its functionalities and their relationships with the material object itself.

Encountering a musical instrument never leaves one indifferent and usually arouses a feeling of curiosity close to admiration towards this alloy of matter, form and sound. Though it always seems to be conceived and produced in order to be listened to, the stories that it can tell are numerous.

An instrument can be a simple object in appearance or a clever assembly of tools and sound materials. It can be entirely conceived and designed as a new object or it can result from repurposing an artefact from its primary function (musical stone, washboard, musical glasses, ....).

The perception of an old musical instrument is complex. Its forms and plasticity as they appear to us nowadays are sometimes a very distant reflection of what they were originally. Its sound,

\footnotetext{
${ }^{1}$ In this paper, perception refers not only to the processing of sensory information but also to the understanding of the instrument in societal, historical and cultural terms
} 
when it still exists, has suffered as well due to ageing. Some instruments do not have a sound anymore because they cannot be played, or because the playing technique or the musical practice are lost. Therefore, the perception of this material and sound object relies on different senses, among which the sight is probably the most important. The involved senses provide the audience member the informations, on which they shape an identity to the instrument that is presented to them. Starting from a definition of the old musical instrument, we propose here, through chosen examples, to show how the input of sciences (both natural and human) allow the supply of factual elements which provide the instrument, beyond its sound, with a common sense based on "objective" documentation, that can be shared by a large audience.

\section{The old musical instrument}

\subsection{Attempts towards a definition}

Identified within a culture, a musical instrument is the product of an era to which it seems sometimes difficult to constrain it. It is indeed common that an instrument, like the guitar or the harpsichord for instance, that was thought to be forgotten was actually reused at a later time, in quite different musical ways, showing sometimes potentialities which were unexpected at the time of its original conception. The notion of old instrument is therefore difficult to define. Is it about an instrument newly made from an old template? Is it about an instrument that we can show, by an analysis of its material (dendrochronology if it happens to be in wood [2]), that one part or the whole instrument dates from an old time relative to the observer and on which it would not be possible to play a contemporary repertoire?

When a relatively long period of no use exists in the history of the instrument, the definition becomes easy. This period of abandonment, comparable to the period of burying of an archaeological object, is the guarantee of the testimony of another time. It places objectively the instrument in a time period, based on which the observer (scientist, musician, curator, general audience, ...) builds the mental image of a temporal distance. In this case, the evocative power of the instrument is not constrained to a "simple" auditory dimension, as the passage of time has stamped the whole object with various and complex significations and dimensions. Listening, seeing, touching, playing such a musical instrument is an open door to the time as highlighted by Robert Barclay: "Historic musical instruments have a very special place in modern society. They are touchstones to the past to an extent that other artefacts are. Playing music upon them allows us briefly to bridge the gap between the here and now and the over and done with" [3].

On the other hand, when such abandonment period does not exist, defining the epoch of an instrument and thus defining what an old instrument is becomes very complex, as we will see in the particular case of the violin.

\subsection{Particular case of the violin}

Since its first appearance in the 16th century, the violin did not have to suffer a period of abandon and has been continuously played. It possesses, even now, a very privileged place in the European instrumentarium. Numerous are the musicians who are specialist in contemporary repertoire but play on instruments with a famous signature from the 18th century. The famous third partita for solo violin (BMW 1006) composed by Johan Sebastian Bach in 1720 was played on the violin made by Nicolas Lupot in 1803, kept in the collection of Musée de la Musique in Paris (figure 1), during 
the opening ceremony of the new museum in 1995. A few years later in 2002, the same violin allowed to hear the piece for solo violin written by Ianis Xenakis in 1950, in a tribute concert to this composer. From which period really is this instrument? Is it even from a precise period? What is the real signification ot the manufacture year still visible on the authentic maker's tag inside the instrument? What do we hear in each concert: a violin from 1995 or 2002, date of the concerts? An instrument from 1720 or 1950, dates of the creation of the pieces? Or an instrument from 1803 which has the incredible capability of being used for both music written way before and way after its fabrication?
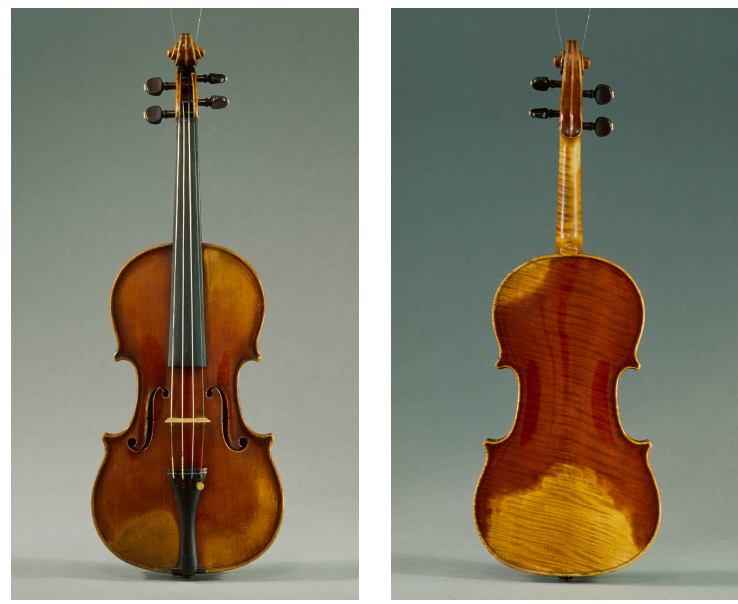

Figure 1: Violin made by Nicolas Lupot (E.996.10.1, Collection of Musée de la Musique - Paris [13]). Sometimes called "The French Stradivari", Lupot was very active in Paris at the beginning of the 19th century. His instruments are largely inspired by Stradivarius models, which he was able to access thanks to his reputation as a repairer. The label inside the violin reads "Nicolas Lupot luthier rue de Grammont à Paris l'an 1803". Its neck was changed at least once and its set-up is typical of the first half of the 20th century, as indicated by its "Émile Français Paris" iron-stamped bridge. Copyright Cité de la musique - Philharmonie de Paris

Defining an old violin is not easy. The transformations, that the instrument has necessarily undergone during successive maintenance to be kept in playing condition, make it change era. During the 19th century, Parisian instrument makers were particularly active in the development of conservation techniques, some of which are still being in use. The study of technical treatises written by luthiers in the 19th and 20th centuries shows how the definition of an old violin can be ambiguous [4]. For them, it is an instrument which body (mainly the exterior and visible elements of it) has kept traces of its origin. These traces are magnified by the patina, a mark of regular and continuous use, representing the time passing but mainly the continuity of the instrument's existence, certainly old, but eternal as the instrument belongs to the past as well as to the present. Thus, the transformation of the neck and some other functional elements, which are well known to play an important role in the tone quality, are swept away like details as soon as they do not modify this immediate and mainly visual perception. "Le rebarrage des tables et le changement des poignées étant des réparations et non des modifications, ces instruments sont donc tels qu'ils ont été construits" (Changing the bracing of the plates and the neck being repairs but not modifications, these instruments are thus as they were made) wrote Laurent Grillet in his famous work Les ancêtres du violon et du violoncelle [5], talking about some famous violins of his time. Beyond the fact that this argument can be seen as weak in the light of the so called Theseus paradox (a thought experiment that raises the question of whether an object that has had all of its components replaced remains 
fundamentally the same object), it still shows an interesting change in paradigm as braces of the plates and neck would nowadays be considered as constituant parts of the instrument (rather than secondary accessories in Grillet's time).

\section{$3 \quad$ Perception of old instruments induced by visual inspection}

Before it even sounds, a musical instrument is seen, as a material object. Whether the observer is expert or novice, the visual examination which is conducted leads to a quick categorisation in function of his/her degree of expertise. "This instrument is obviously old, juts by looking at it!" "This instrument seems to come from Asia, its decorations are typical of Chinese lacquers from the 18th century." "The decorations of the papers show that it is a Flemish harpsichord". The documentary and material approaches to identify the origin of a musical instrument and thus certify its authenticity are mostly guided by sight (rather than by hearing) and often only question the initial hypotheses derived by an initial visual perception. When the instrument belongs to different epochs or different places because of different organological modifications (for instance, a Flemish harpsichord from the 17th century which underwent a large renovation in France in the middle of the 18th century), there is often a conflict between the visual perception and the multiple origin of the instrument. When these modifications are subtle, discrete and frequent and the instrument has always been used in the instrumentarium, then it belongs simultaneously to many epochs. This is the case of the violin, which has been shown above to represent a real archetype on this matter and therefore has appeared relevant to us to pursue further our reflection and our experimental approach.

\subsection{Case of old violins kept in playing condition}

Stradivari and Guarneri 'del Gesu' may well be the greatest violin makers ever, but it takes an expert opinion based on visual and historical (rather than tonal) evidence to say whether a particular example is genuine. Playing and listening tests never enter the authentication process. However, the violins of these two masters as well as other Italian makers of the 17th and 18th centuries are widely believed to possess playing and sound qualities that are both immediately discernible to experienced violinists and not found in new instruments ${ }^{2}$.

Recent studies $[7,8]$ have shown that, when blind-folded, players prefer in average new instruments and cannot tell better than chance level whether a violin is old or new. This highly suggests that the origin of the tonal superiority of the Old Italian violins is not grounded in particular playing and sound properties of the violins but in the knowledge that the violinists have of their origin and age. Through top-down processes, this knowledge changes the perception at a neural level [9]: simply knowing the history or pedigree of an instrument can activate expectations for its sound that cause neural circuits - even lower level sensory-perceptual ones - to behave differently than they would without that knowledge. Violinists may really believe that the instrument sounds better, even if there is no acoustic difference in the physical world.

However, though these studies, along with many informal studies since the beginning of the 20th century, have shown that new violins are in general more efficient as musical tools for soloists

\footnotetext{
${ }^{2}$ Testimonies are numerous. For example, we can refer to Simone. F. Sacconi, famous maker of the 20th century, author of "Il secreti di Stradivari" [6] in which he reported the testing of a Stradivarius cello at Carnegie Hall, during which a famous player, deliberately sitting in the gallery, turned around instinctively from the first few notes, with the impression that the instrument was behind him.
} 
nowadays, the interest for these violins as well as their price have not decreased. This shows that these instruments are now part of our cultural heritage like old paintings for instance.

\subsection{Case of museum violins}

Perception is the the complement of materiality and their relationship can be more or less direct. In the case of a musical instrument, this perception is at least double, auditory and visual. While the first one is probably the most important one during a concert, the second one prevails in a museum. Sound, form and colour maintain complex relationships. If the material dimension of an instrument can be grasped even if in an incomplete conservation state, its tone, to be perceived, requires the instrument to be complete, and moreover, to be played by a musician. However, it can be present in the imagination of the audience, who will refer to their memory to "hear" the instrument that they see. Thus, similarly to the face that a listener imagines when hearing a voice on the radio, the sound imagined by a spectator is linked to the aesthetic and visual aspect of the instrument that he looks at. Has a dark sounding violin a dark colour? The question asked this way may appear simplistic. However, the answers collected to a series of questions asked to 29 observers (10 violin makers and 19 musicians) about two violins, of trifling and recent make, one with a brown varnish, the other one with a golden yellow one, presented to the observers in the same conditions, allowing them to see the instruments from all perspectives but not to touch them, are disturbing. After having been asked to describe both violins, the participants were asked about how they imagined the sound of the two violins. While 23 participants described spontaneously only the physical objects in terms of shape, colour, ..., without any consideration on their sound, only 2 of them (bowed string players) could not answer the second question. Among the 27 who described how they imagined the sound, a clear difference could unsurprisingly be observed between the makers and the musicians. For the first ones, their imagination of the sound was based on "objective" parameters of the making and the wood. Thus, 8 out of 10 talked about the "voûtes, mailles du bois, assez plat sous le chevalet, travail fin, pores serrés" (arches, medullary rays, quite flat under the bridge, fine work, tight pores). For the latter, their imagination of the sound was mainly (15 out of 19) induced from the colours (two players mentioned one the bridge, the other one the making, and two others could not answer the question).

What is more interesting is the relative consensus on the sonority of each violin and how the difference in imagined sonority is clearly linked to the difference in colours. The brown violin was imagined as richer, warmer, rounder, more flexible, more powerful than the yellow violin which was, conversely, considered as less complex, harsher and more nasal, stiffer and tighter, less powerful.

Beyond this perceptual assessment, the symbolic history of colours brings to these results an additional historical and social dimension. The red colour in a western society takes on a particular importance ${ }^{3}$. The analytical results obtained these past years $[11,12]$ on a panel of more than hundred instruments of the violin family, mainly from the 17 and 18th centuries, show the presence of red pigments (vermilion, cochineal, madder), particularly in the Italian craftsmanship and more generally in the instruments made by makers whose reputation was already assured during their life. This is confirmed by the analysis of the 242 descriptive notices (in French) from the database of the Musée de la Musique's collection [13] which shows that $62 \%$ of the 18th century violins from Italian origin have a varnish described as red ${ }^{4}$ while this is the case for only $25 \%$ of same period

\footnotetext{
3 "Le rouge vient en dernier dans l'oeuvre alchimique" (Red comes last in the alchemical work) writes the alchemist Norton de Bristol in the 15th century [10].

${ }^{4}$ There is no standardized way of describing the colour in the notices and so the varnish description can depend strongly on the perception of the person who wrote the notice( "jaune doré" (golden yellow), "brun orangé" (orange
} 
violins from French origin. However, there is an important change during the 19th century, as a red varnish appears in $78 \%$ of the notices of French origin violins from the 19th century and $91 \%$ from the 20th century.

Table 1 shows that the colour of the varnish is much less described for violins from the 19th and the 20th centuries (more than 20\% of the notices do not contain information on the colour), than for violins from the 19th and the 20th (less than 10\%). However, there are a relatively large number of "experimental" violins in the 19th and 20th centuries, for which the colour is never described. Having experimental status, as the Savart violin has, is the only property perceived to have value; therefore, the color does not seem interesting enough for the curator to describe. Thus, if we remove the experimental violins from the database, the number of non described notices is only twice as large for the 19th century than for the other centuries.

\begin{tabular}{|c|c|c|}
\hline & full database & database without the the experimental violins \\
\hline 17 th & 8 & 8 \\
18 th & 7 & 7 \\
19 th & 24 & 19 \\
20 th & 21 & 10 \\
\hline
\end{tabular}

Table 1: Percentage of violins of Musée de la Musique's collection not described in terms of colours for each century, when considering the full database and when removing the violins considered as experimental.

The predominance of the red varnish in the 19th and 20th centuries as well as the fact that 19th century violins are much less described can be explained by the fact that all along the 19th and then 20th centuries, the old instrument has been invented and become archetype. Development of conservation techniques, appearance of large national collections, presentation of copies of old instruments in universal exhibitions take part in its conquest by the opinion and results in a production mainly based on copies of the old masters work. Therefore, an old varnish is more highly considered as a recent varnish, and only the varnishes from the 17th and 18th can have this status of "old varnish". Thus, their description - in particular their colour - appears, to the curators eyes, much more important than for more recent varnishes. This shows that the museal look is not neutral but as well that the varnish is constituent of the work in the case of the violin, unlike for paintings, whose varnish is often removed to be changed. In addition, the making school of reference is the Italian school, Cremonese and Venitian in first place, in which the famous and influential masters - Stradivarius, Amati, Guarnerius, Gofriller - largely used a red varnish in their production. All these reasons thus explain the enthusiasm for red varnishes in the 19th and 20th centuries which is well illustrated by the following quote from the maker and musician Auguste Tolbecque: "C'est ainsi qu'un Stradivarius un peu plus rouge qu'un autre vaut de suite dix mille francs de plus" (This is how a Stradivarius a little more red than another one costs directly 10000 francs more) [14].

brown), "rouge brun" (red brown), ...). In addition, there are some chemical processes which, with time, can affect the original colour. For example, yellow resins have a natural tendency to become brown due to oxidisation. It is therefore not very easy to know the original colour of the violins based on their descriptive notices. However, red pigments are easily recognizable and would appear in some ways in the description, so we have therefore decided to group varnish colours in two categories: 'red' and 'not red'. 


\section{How science can change or enrich this perception}

\subsection{The input of scientific documentation}

Our perception of the instrument is global. How we imagine its musical possibilities and its sound is linked to the visual examination of the object as illustrated with the example described in the previous section showing a direct relationship between how observers imagined the sound of a violin and the colour of this violin. But mechanical and acoustical analyses can provide objective informations which can modify our a priori and enrich our understanding of the instrument. Two illustrative examples among many are given below.

The singular Stroh instruments are hard to classify. Instantaneously categorised as "violin-like instrument" in a listening test, these instruments seem however "half- string, half-wind" instrument (Figure 2). A scientific documentation resulting from a pluridisciplinary collaboration (acousticians, curators, musicians) shows that what could be considered as just curious instruments actually appear to be the work of a talented maker, resulting from the process of the engineer Augustus Stroh to meet his original need, i.e. solving part of the difficulties of the sound recording techniques in their infancy [15]. By shedding light on its genesis and history, and explaining their acoustical functioning, this scientific documentation give these instruments a new place in the instrumentarium and make them integral musical instruments. In this sense, this documentation can disrupt the values likely to be conveyed by the instruments and modify their perception by spectators.
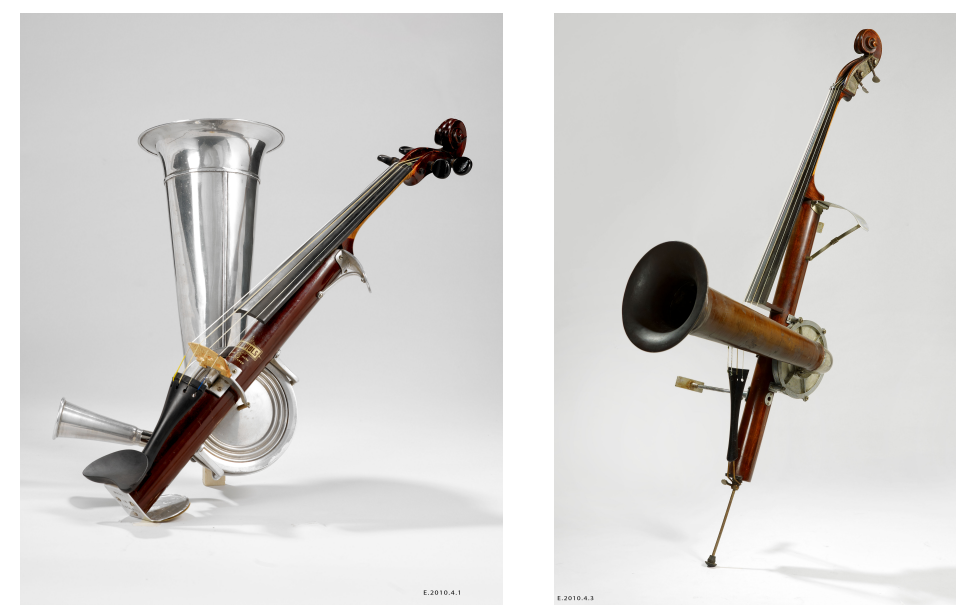

Figure 2: A violin (E.996.10.1, Collection of Musée de la Musique - Paris [13]) and a cello (E.2010.4.3) made by Augustus Stroh, after his patent $\mathrm{n}^{\circ} 9418$ "Improvements in Violins and other Stringed Instrument", filed 4 May 1899 and registered 24 March 1900. Copyright Cité de la musique - Philharmonie de Paris.

Another illustration can be found in the Selmer jazz guitar. In 1931, Mario Maccaferri filed a patent on a guitar with a double resonator. Produced by Selmer, a company renown for its saxophones, this guitar called "big mouth" will be adopted by the famous guitarist Django Reinhart to become, for some time, the emblem of the gypsy jazz guitar. Evicted in 1934, taking back his rights and patents, Maccaferri imposed the company to build a new model, to avoid a conflict of counterfeiting. A new guitar was born as soon as 1935. Its adoption by Django Reinhart would be immediate. The visual comparison between the two instruments is unambiguous (Figure 3): one has a wide oval hole, a neck with 12 frets and a system of simple internal bracing; the other one has a tiny circular hole, a neck with 14 frets and a system of double and reinforced bracing. 


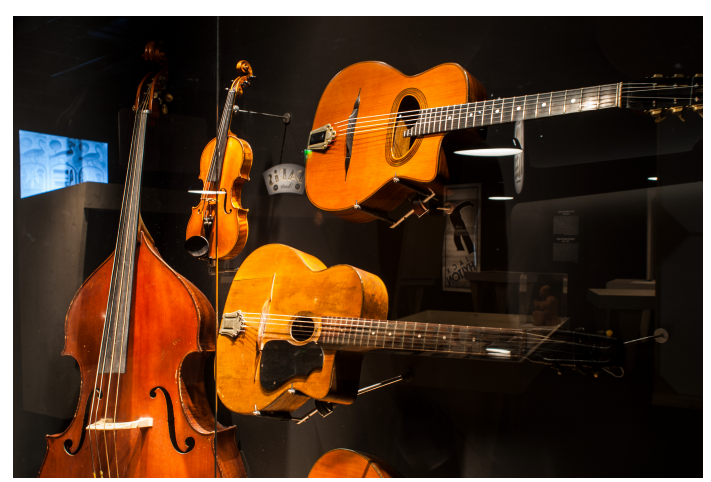

Figure 3: A "big mouth" Selmer-Maccaferri guitar at the top and a "small mouth" Selmer jazz guitar below, as presented during the Django Reinhart exhibition at Musée de la Musique in 2012. Copyright Cité de la musique - Philharmonie de Paris - photo Matthias Abhervé.

These obvious organological differences would normally foreshadow a sound contrast between the two instruments. However, acoustical analyses contradict this assumption. The global responses of both instruments appear similar: the spectral analysis presented in Figure 4 shows a similar distribution of the radiated energy as a function of frequency, mainly spread between 200 and 400 $\mathrm{Hz}$ (band 2). The measured differences between the two guitars are of the same order of magnitude as the differences between guitars of the same model.

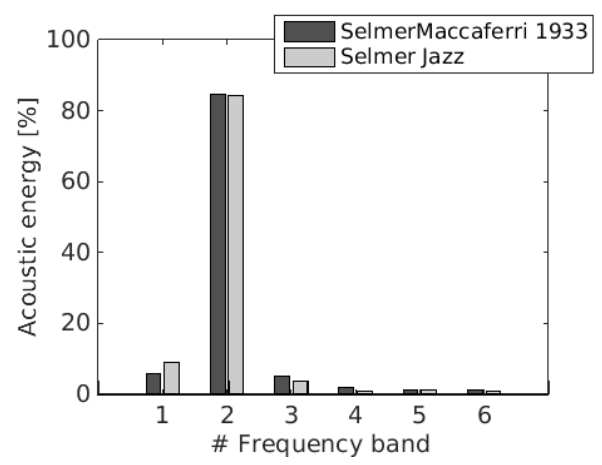

Figure 4: Spectral analysis performed on a chromatic scale played in a similar way on the two guitars presented in Figure 3. The relative energy contained in six frequency bands - [50 200], [200 400], [400 800], [800 1200], [1200 1800] and [1800 2500]- is expressed in percentage of the total energy. Figure by Sandie Le Conte.

\subsection{The complex relationship between science and perception}

Will this contradiction between science and perception (induced by visual inspection) eventually modify the global perception? The answer is complex because the global perception and understanding of an instrument is linked to its cultural and symbolic status as well as its physical appearance.

As demonstrated by many historical examples, scientific investigations in the field of mechanics seem to coexist with the magic around musical instruments rather than suppress it. For instance, in 1761, based on the first ideas of the Irish Richard Puckeridge, Benjamin Franklin presented the glass harmonica ${ }^{5}$, whose sounds are produced by finger friction on tuned glass bowls. Accused

\footnotetext{
${ }^{5}$ The famous composer Gaetano Donizetti used it in its opera Lucia di Lammermoor, created in Napoli in 1835.
} 
of being responsible for premature deliveries or the weakening of the strongest man in less than an hour, this instrument was forbidden by a police decree in some German cities in 1835 and disappeared rapidly from the instrumentarium before being rediscovered later in the 20th century. Thirty years earlier, in 1802, the physicist Ernst Florens Friedrich Chladni described very precisely, in his famous work Die Akustik [2], the geometric figures which result experimentally from bowing glass or metal plates. Then, in 1822, Joseph Fourier laid out the mathematical foundations for the theory of decomposition in series of sinusoidal signals [3]. As we can see, the scientific tools allowing an explicit formulation of the phenomena involved in the glass harmonica were already available at the time of its official ban, without having tarnished the magical dimension attributed to this musical invention.

Another example is the case of the violin. Since the end of the 19th century, many blind listening and playing tests [18] have shown a preference towards new instruments compared to the old Italians as well as no systematic ability of players to recognise them. However, violinists (even some soloists who took part in the recent scientific studies $[7,8]$ !) continue to claim such statements as "the one thing that you cannot put into a new violin is that it's been played for 300 years - these instruments change and develop" [19]. Therefore, although those studies could appear as "the final nail in the coffin for those who would believe that old musical instruments sound demonstrably better than new instruments," they are "unlikely to change many musicians' minds" [9] and Stradivarius legend and the magic behind his instruments will remain mostly unaffected by science.

The example of the violin is actually not isolated and many instruments (at least in the Western society) carry in their history the construction of myths, regardless of scientific studies. The electric guitar, a more recent addition to the instrumentarium, is another example. Leo Fender's guitars have become emblematic instruments, similar to the Stradivarius, and the reputation of these instruments will likely remain unaffected by recent scientific work [20,21].

Many musical instruments can acquire a leading role in the cultural identify of a population just as the electric guitar is easily associated with the 20th century North American culture. Human sciences, by shedding light on the cultural and symbolic dimensions of these instruments, enlarge their significance and enrich our perception of them. For example, various legends describe the origin within the Mongolian culture of the vielle morin huur (represented in Figure 5), which was added to the Unesco World Heritage in 2008. The generic Mongolian term huur refers to all cordophones and morin huur literally means a huur with a horse head. This vielle is closely associated with pastoral life as it punctuates the daily activities during the sedentary periods and the seasonal migrations ${ }^{6}$. It generally accompanies tales and legends but possesses as well the power of preserving herds from diseases and evil spirits. This vielle matters as much to herd keepers as their own horses. The assembly of its eight components is achieved in a particular ceremony and the instrument cannot be played before the horse head has been coated with butter or cream. The intimate relationship with the horse is not just material (through the horse head) but is symbolic too. It is said that some monotonous chants played by morin huur artists reproduce the sound of the gallop in the steppe. Nowadays, the art and the technique of playing are changing. New musical approaches are leading to organological modifications. Tomorrow, the morin huur may be silent forever or newly played across the world. Either way, the horses' gallops will have moved away. But the scientific investigations of the instrument and its history, formalising and conceptualising the knowledge that has accompanied its origin, will offer audiences the keys for understanding this instrument. Beyond

\footnotetext{
${ }^{6}$ See the documentary film [22] which presents a poetic and well documented description of the vital importance that the instrument can represent.
} 
the existence of the object itself, these studies will allow this instrument to be the vehicle and the survival tool of an oral culture in movement.

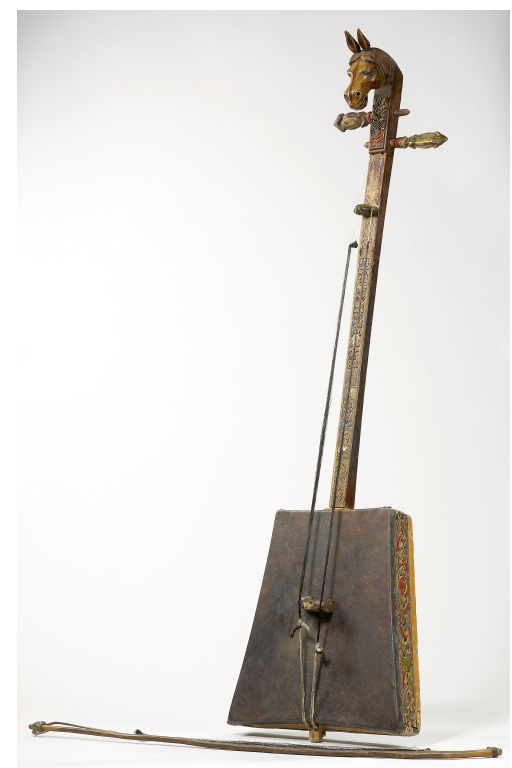

Figure 5: Viele morin huur (E.2009 2.1, Collection of Musée de la Musique - Paris [13]). Copyright Cité de la musique - Philharmonie de Paris

\section{Conclusion}

As illustrated in this paper, an old musical instrument cannot just be perceived as a simple music tool as it happens to be the vector of cultural, esthetical, technical, historical values, which are invisible to visual inspection. A multidisciplinary scientific study and documentation is therefore necessary for us to perceive these multiple identities [23] and modify and enrich our contemporary eye.

So is the case of the lute. As testified by iconography, it was a musical instrument which was really played and present in all social classes during the 17 th century. Nowadays, it is reserved to interpretations called "historical" and occupies only an anecdotal place in the current musical landscape. De facto, it is generally perceived as an obsolete instrument. This however does not take into account the role, litlle known, that it seems to have played in the history of the western modern thought. The lute was indeed also used as an experimental scientific tool by Vincenzo Gallilei, to demonstrate that the frequency of a vibrating string changes as the square root of its tension. ("Discorso interno alla diversita delle frome del diapason" probably written in 1589, rediscovered by Claude Palisca in the 1960s and translated in [24]). This result contradicted the commonly accepted theory due to Pythagoras that the frequency should change linearly with the tension. As accepted theories of nature were tied to religious beliefs, contradicting such theory had implications far beyond the musical world [25].

Old musical instruments represent thus an exceptional material archive containing information about humankind's technical knowledge, sensibilities, beliefs and dreams. A full understanding of an old musical instrument requires a pluridisciplinary study which addresses the technical, artistic, religious, cultural and historical dimensions of this archive. Such study enriches our global perception of what the instruments were or are. In fact, an old musical instrument may not always be 
what we think it is.The question of hearing it can then become completely irrelevant ...

\section{Acknowledgements}

The authors would like to thank Sandie Le Conte and Timothy Wofford for fruitful discussions as well as CNRS and Cité de la Musique - Philharmonie for supporting this research.

\section{References}

[1] Sève B. L'instrument de musique, une étude philosophique, l'ordre philosophique, Ed. du Seuil, Paris, 2013, p. 151-176

[2] K. Kufar. "A review on dendrochronology". J. Cult. Herit. (same special issue), 2017, p. xx $\mathrm{xx}$.

[3] Barclay R. The preservation and use of historic musical instruments : display case or concert hall? , Earthscan, London, 2004, p. 1.

[4] Marconi E. and Vaiedelich S. "Concevoir la restauration du violon au XIX" siècle", Actes du colloque Le violon en France du XIX ${ }^{e}$ siècle à nos jours, dir. C. Fritz \& S. Moraly, Paris, 22-24 mars 2015. In press.

[5] Grillet L. Les ancêtres du violon et du violoncelle, Charles Schmid, Paris, 1901.

[6] Sacconi S.F. Les "secrets" de Stradivarius, Ed. Castelli and Bour'His, Cremona, 1989, p. 105106.

[7] Fritz C., Curtin J., Poitevineau J., Morrel-Samuels P. and Tao F.-C. "Players preferences among new and old violins". Proceedings of the National Academy of Sciences of the USA. 109(3), 2012, p. $760-763$.

[8] Fritz C., Curtin J., Poitevineau J., Borsarello H., Wollman I., Tao F.-C. et Ghasarossian T. "Soloist evaluations of six Old Italian and six new violins". Proceedings of the National Academy of Sciences 111(20), 2014, p. 7224-7229.

[9] Levitin D. "Expert violinists cant tell old from new". Proceedings of the National Academy of Sciences 111(20), 2014, p. 7168-7169.

[10] Ball P. Histoire vivante des couleurs, 5000 ans de peinture racontée par les couleurs, trad. Jacques Bonnet. Ed. Hazan, Paris, 2005, p. 81.

[11] Echard J.-P., Bertrand L., von Bohlen A., Le Hô A.-S., Paris C., Bellot-Gurlet L., Soulier B., Lattuati-Derieux A., Thao S. , Robinet L., Lavédrine B. and Vaiedelich S. "The nature of the extraordinary finish of Stradivari's instruments", Angewandte Chemie International Edition, 2009, p. 197-201.

[12] Échard J.-P. and Bertrand L. "Complementary Spectroscopic Analyses of Varnishes of Historical Musical Instruments", Spectroscopy Europe 2, 2010, p. 12-15.

[13]http://collectionsdumusee.philharmoniedeparis.fr/

[14] Tolbecque A. Lart du luthier, Niort, 1903 - Laffitte reprints Marseille 1980, page 136.

[15] Gautier F., Curtit M., Fréour V., Vaiedelich S. and Juarez A.V. "Acoustic characteristics of the Stroh-violin". Proc. of Int. Symp. on Musical Acoustics, Le Mans, 2014.

[16] Chladni E.F.F. Die Akustik. Breitkopf und Härtel, Leipzig, 1802.

[17] Fourier J. Théorie analytique de la chaleur, 1822.

[18] Coggins A. "Blind faith". The Strad 118, 2007, p. 52-55.

[19] Belluck P. "A Strad? Violinists can't tell". The New York Times, April 8, 2014, p. D4. 
[20] Navarret B. Caractériser la guitare électrique : définitions, organologie et analyse de données verbales. PhD dissertation, Université Paris 8 , France.

[21] Paté A., Navarret B., Dumoulin R., Le Carrou J.L., Fabre B. and Doutaut V. "About the electric guitar: a cross-disciplinary context for an acoustical study". Proc. of Acoustics 2012, Nantes, France.

[22] L'Histoire du chameau qui pleure, film documentaire réalisé par Byambasuren Davaa, 2003.

[23] Lacombe H. "L'instrument de musique : identité et potentiel", Methodos 11, 2011.

[24] Baskevitch F. "Musique et sciences à Florence à la fin du XVI siècle : la Camerata et les Galilei", in Art et Sciences à la Renaissance Collectif, dir. E. Barbin, Ellipses Paris, 2007, p. 201-202.

[25] Lindsay R. B. "The Story of Acoustics." The Journal of the Acoustical Society of America 39, 1966, p. $629-44$. 